\title{
TESTING AND MODELING LIQUEFYING FUEL COMBUSTION IN HYBRID PROPULSION
}

\author{
A. Weinstein and A. Gany \\ Faculty of Aerospace Engineering \\ Technion - Israel Institute of Technology \\ Haifa 32000, Israel
}

\begin{abstract}
Hybrid motors are considered an alternative for space launchers due to their safety and high energetic performance. Nevertheless, classical hybrid combustors employing polymeric fuels are characterized by a low fuel regression rate resulting in low thrust levels that may not be adequate. This research presents experimental investigation and theoretical model of liquefying (paraffin-based) fuels, featuring high regression rates. The model developed includes an additional feature and mass loss mechanism, i. e., the liquid melt flowing along the grain. The test results exhibit a good correlation with the model predictions.
\end{abstract}

\section{INTRODUCTION}

Hybrid motors consist of fuel and oxidizer components in different physical states. Polymeric material is typically used as a solid fuel. It is placed in the combustion chamber as a hollow-cylinder grain with a single port or multiple ports. Oxidizer can be chosen from a variety of oxidizers used in liquid rocket engines. It is injected into the fuel port(s) in a liquid or gaseous form. The combustion occurs in the gas phase within the boundary layer over the surface of the solid fuel grain. Often, the combustion chamber includes an aft mixing chamber to allow further mixing and combustion of unburned propellant species. Overview and history of hybrid propulsion are presented by Altman and Holtzman [1].

Energetic performance of hybrid motors is comparable to liquid rockets and are better than solid rockets due to the use of more energetic liquid oxidizers. Hybrid systems can provide a simpler throttling procedure compared to liquid rockets (via control of only the oxidizer flow rate) as well as shutdown and on/off capabilities which are practically unavailable in solid rockets. It might be significant for precise orbit insertion or space operation. The phase separation between the fuel and the oxidizer increases the safety during motor development and operation, since no explosion or major fire can occur upon accidental contact

This is an Open Access article distributed under the terms of the Creative Commons Attribution License 2.0, which permits unrestricted use, distribution, and reproduction in any medium, provided the original work is properly cited. 
between the fuel and the oxidizer. In addition, the hybrid motor operation is insensitive to cracks or defects in the fuel grain, since the fuel regression rate is related to the oxidizer flow rate and to the heat flux from the bulk flow to the surface. Another significant advantage of hybrid motors is the option of "green" propellant combinations of minimum environmental impact.

The most significant potential use of hybrid motors is for large space launch boosters. The combination of safety, "green" propellant, and high energetic performance (especially when using liquid oxygen (LOx) as the oxidizer), is particularly attractive.

Hybrid systems are characterized by a low fuel regression rate typically an order of magnitude lower than that of common solid propellants. For many potential applications, particularly for space launch boosters that require high thrust levels, it is a major drawback. This has motivated launching a search for high regression rate fuels.

\section{New Trend of Enhancing Fuel Regression Rate}

As mentioned above, different applications of hybrid motors, particularly for space launchers, require a high thrust, which implies higher overall fuel consumption rates. To avoid the complex multi-port grain configuration, a new direction has been proposed and investigated in recent years: the use of high regression rate, liquefying fuels, mostly paraffin-based fuels.

A most comprehensive experimental and theoretical work on paraffin fuels has been conducted by Karabeyoglu et al. [2-6] at Stanford University. They suggested that a very efficient way to increase regression rate of hybrid systems is to use a fuel that during combustion will generate mass transfer by mechanical means in addition to the mass transfer by gasification. For materials forming a low viscosity liquid (melt) layer on the surface during their combustion, mechanical mass transfer can take place by droplets entrainment into the gas stream.

The hybrid diffusion flame theory was generalized to hybrid fuels that form a liquid layer on the surface during burning. It was shown that the relatively thick liquid layer formed may be unstable under hybrid operating conditions. Several investigations were conducted in different universities [7, 8] and are summarized by Gany and Lazarev [9]. Several additional works of interest have been published since [10-12].

\section{EXPERIMENTAL SYSTEM AND RESULTS}

\section{$2.1 \quad$ Experimental Setup}

A laboratory scale static firing test setup including a motor (combustion chamber), a test stand, a gaseous oxygen tank, measuring gauges for the thrust, the 
pressure, and the flow rate, and a computerized data acquisition and control system has been used for the experimental investigation. The combustion chamber consisted of a single-port, 21-millimeter initial diameter and 190-millimeter long paraffin fuel grain. At the aft end of the combustor there was a water-cooled mixing chamber, 42-millimeter internal diameter and 120-millimeter long. A choked converging (only) motor nozzle has been used in the experiments. Gaseous oxygen has been used as oxidizer. Test sequence included opening the oxygen valve prior to the ignition. The motor ignition was accomplished by introducing a small amount of ethylene gas into the oxygen flow for a short time at the beginning of the test, and igniting by a spark plug. Oxygen flow rate was controlled and measured by a replaceable choked nozzle in the oxygen supply line. The present configuration allows oxygen flow rate up to about $40 \mathrm{~g} / \mathrm{s}$, yielding oxygen mass flux as high as $100 \mathrm{~kg} /\left(\mathrm{m}^{2} \mathrm{~s}\right)$. The combustion chamber pressure could be roughly estimated before the test by selecting the exit nozzle throat diameter. Typical chamber pressure was about $15 \mathrm{~atm}$ (about $1.5 \mathrm{MPa}$ ), ranging between 12 and 18 atm. Nevertheless, the pressure effect is known to be minor for the hybrid combustion. The setup used in the present research is presented in Fig. 1.

The paraffin used for the investigation was MW-704, with melting point of $70-74{ }^{\circ} \mathrm{C}$ and density of $747 \mathrm{~kg} / \mathrm{m}^{3}$. The test motors were prepared by casting molten paraffin into the vertically positioned motor case. The port was created by placing a cylindrical pin along the centerline of the motor during casting. Paraffin fuel tends to shrink during cooling and solidifying, so at the end of the process additional molten paraffin was added to the grain. There were no gaps between the paraffin layers since hot paraffin melted the adjacent cooler layer and there was a good gluing between the layers. Also no gap was noticed between the paraffin and the motor case.

Since the fuel regression rate is related to the oxidizer flow rate, it was difficult to reach high $\mathrm{O} / \mathrm{F}$ ratio by merely increasing the oxidizer flow rate. In order to

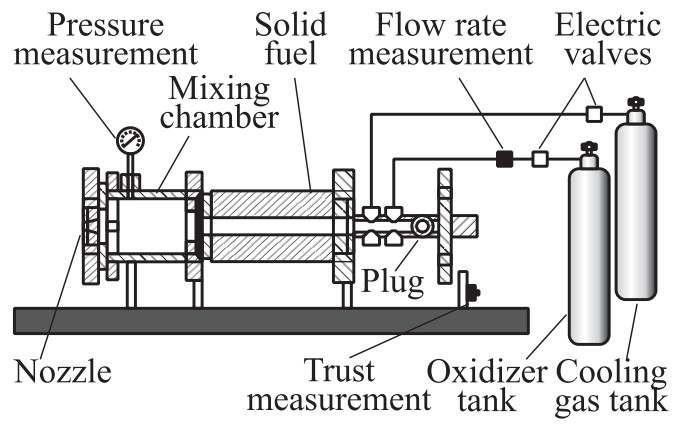

(a)

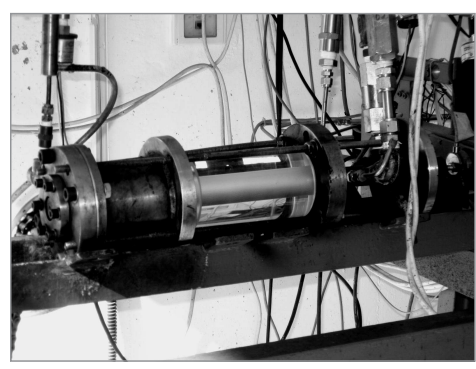

(b)

Figure 1 Schematic $(a)$ and picture of the test setup (b) 


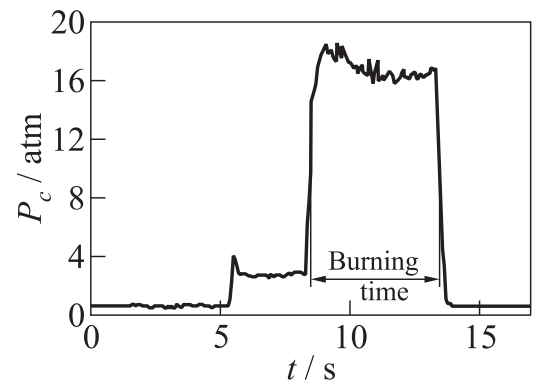

Figure 2 Typical static firing test output. Preignition pressure rise is due to the oxygen flow

obtain higher levels of the $\mathrm{O} / \mathrm{F}$ ratio, shorter fuel grains were tested in addition to the regular ones, while keeping the high oxidizer flow rate. Both $95 \mathrm{~mm}$ and $63 \mathrm{~mm}$ grain lengths (a half and a third of the original grain length, respectively) were used.

The pressure output of a typical test is shown in Fig. 2. The burning time of each firing test was $5-8 \mathrm{~s}$, which is long enough to assume fully developed combustion while keeping small enough changes in internal diameter of the grain for using average values. The burning time was taken from the $50 \%$ of the pressure rise to $50 \%$ of the pressure drop. The data sampling rate was $10 \mathrm{~Hz}$.

\section{$2.2 \quad$ Results}

The fuel regression rate is an important parameter in the internal ballistics and overall performance of hybrid motors. The time and space average regression rate was calculated from the fuel mass loss and burning time. Each motor was weighed before and after firing to obtain the overall fuel consumption during the test. Burning time was obtained from the test output as shown in Fig. 2. The relatively short test duration $(5-8 \mathrm{~s})$ helped to avoid large variations in port diameter, mass flux, and fuel regression rate during the test. Figure 3 presents the dependence of the regression rate of pure paraffin on the oxidizer

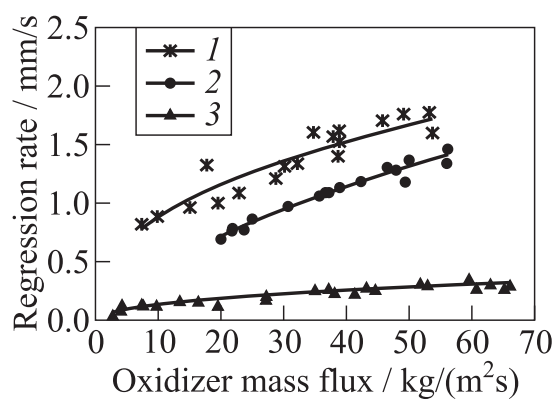

Figure 3 Comparisson of experimental regression rate of different fuels vs. oxidizer (gaseous oxygen) mass flux: 1 - plain paraffin 704 (current research); 2 - paraffin SP-1 [5]; and 3 - polymer PMMA (current research) 
mass flux. The results are compared to the regression rate data of poly(methyl methacrylate) (PMMA) polymeric fuel obtained in this research from a series of experiments conducted in the same experimental setup as the paraffin fuel. The results are also compared to the experimental results obtained Karabeyoglu et al. [5] for paraffin SP-1.

The regression rate of the plain paraffin obtained in the current research was about 5 times higher than that of the classic polymeric hybrid fuels. Power curve fit for each fuel is plotted to show the regression rate correlation with the oxygen mass flux.

The regression rate correlation obtained from the experimental data for the plain paraffin MW-704 is:

$$
\dot{r}=0.36 G_{\mathrm{ox}}^{0.40}
$$

where $\dot{r}$ is the time and space averaged regression rate of the fuel in $\mathrm{mm} / \mathrm{s}$ and $G_{\text {ox }}$ is the average oxidizer mass flux in $\mathrm{kg} /\left(\mathrm{m}^{2} \mathrm{~s}\right)$.

The average fuel regression rate $\dot{r}$ calculation is based on the overall fuel mass loss during the firing test, and the oxidizer mass flux is calculated from the oxidizer flow rate $\dot{m}_{\mathrm{OX}}$ and average port cross section area

$$
G_{\mathrm{ox}}=\frac{8 \dot{m}_{\mathrm{ox}}}{\pi\left(d_{i}^{2}+d_{f}^{2}\right)} .
$$

Figure 4 presents delivered characteristic velocity $C^{*}$ values of plain paraffin obtained from experimental measurements compared to theoretical calculations obtained from thermochemical program PEP plotted vs. the oxidizer to fuel $\mathrm{O} / \mathrm{F}$ ratio. Most of the test results exhibit $C^{*}$ efficiency of $90 \%-95 \%$, though few yield values of $80 \%-85 \%$. Uncertainty in the overall burning time may be up to about $8 \%$ (e.g., $0.5 \mathrm{~s}$ over an overall burning time of $6 \mathrm{~s}$ ). This is the main cause for experimental errors. It may lead to $8 \%$ error in the fuel regression rate and the

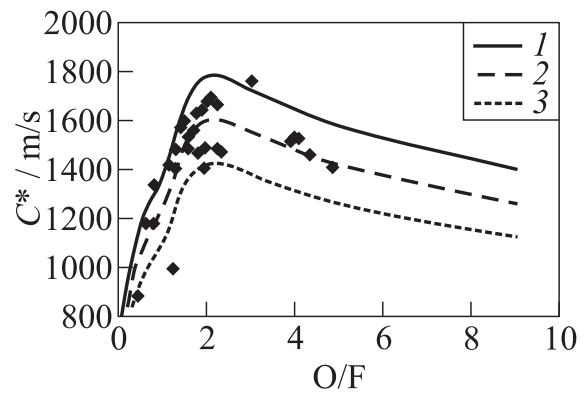

Figure 4 Characteristic velocity $C^{*}$ vs. oxidizer to fuel $\mathrm{O} / \mathrm{F}$ ratio for plain paraffin. Theoretical calculations: $1-100$ percent efficiency; $2-90$; and $3-80$ percent efficiency. Signs refer to the experiments with paraffin 704 
fuel mass flow rate. The oxygen mass flow rate measured via choked orifice is accurate within about $3 \%$. Thrust and pressure measurements error is about $1 \%$. The resulting error in characteristic velocity and specific impulse is, thus, about $5 \%$, and that of $\mathrm{O} / \mathrm{F}$ ratio may reach $10 \%$.

The plain paraffin undergoes severe melting resulting in the generation of a relatively thick molten layer over the burning surface. This phenomenon may result in some unburned fuel leaving the combustion chamber in the form of droplets and burning outside, potentially somewhat lowering the combustion efficiency. The large exhaust flame observed during the motor firing indicates the combustion of unburned fuel outside the motor. In addition, certain amount of unburned fuel was found at the bottom of the aft mixing chamber after firing tests, especially at low oxidizer flow rates. It was collected and added to the grain mass after combustion for performance and efficiency calculations. Hence, performance calculations in the static tests were not affected by this remaining mass. However, in actual motors, such remaining unburned mass should be considered as a loss.

\section{THEORETICAL MODEL}

The goal of the model developed in this research is to predict the overall regression rate and the liquid layer thickness of a liquefying (paraffin based) fuel as well as the contributions of different mass loss mechanisms to the overall fuel regression rate during hybrid combustion. In particular, the model includes, formulates, and evaluates the contribution of an additional mechanism that has not been accounted for in other models: the flow of a molten material along the solid surface, its characteristics (e.g., velocity, thickness), its role in the overall fuel mass transfer phenomena, and its possible impact on an actual motor performance.

The classical hybrid combustion is characterized by a gas-phase diffusion flame established within the boundary layer over the burning solid fuel surface. Gaseous oxidizer diffuses from the core flow towards the flame location, whereas fuel gases resulting from the gasifying condensed fuel surface diffuse towards the flame sheet from the opposite direction. Marxman and colleagues [13-15], conducted a detailed modeling of the hybrid combustion in the 1960s and early 1970s. Their initial simplified model assumed an infinitely fast chemical reaction forming an infinitesimally thin diffusion flame sheet, where oxidizer and fuel fluxes met and reacted at a stoichiometric ratio. In addition, Reynolds analogy was used assuming similarity between momentum and sensible enthalpy boundary layers (i.e., similarity between the axial velocity and the temperature) at least throughout the range from the condensed fuel surface to the flame sheet.

The process of paraffin based hybrid fuel combustion occurs in a three phase environment: solid, liquid, and gas. As the fuel reaches the melting point, a thin 
liquid (melt) layer forms on its surface. The liquid layer heats up, reaching the vaporization point at the interface with the gas phase. The fuel vaporization and gasification products enter the port flow and feed the gas phase diffusion flame at some distance from the condensed surface. The melting and vaporization are caused by heat transfer from the flame to the surface of the fuel mainly by forced convection (and to a much lesser extent by radiation) (see, e.g., [13]). Heat conduction is the dominant heat transfer mechanism across the liquid and solid fuel layers.

Karabeyoglu et al. [3, 4] suggested that in liquefying, paraffin-based fuels, the entrainment mechanism in addition to the vaporization process contributes to the high regression rate. Liquid fuel droplets are torn from the liquid layer by the shear stress caused by the turbulent gas flow over the liquid layer, and enter the gaseous free stream. Karabeyoglu et al. conducted a comprehensive work on the entrainment process and the liquid layer stability in liquefying hybrid fuels.

As mentioned before, in the present research we discuss and investigate the characteristics and contribution of an additional mass loss mechanism associated with the flow of the liquid (melt) layer along the condensed fuel surface. Such flow is implied from the shear stress applied by the gas flow over the liquid layer. This mechanism has been implemented in the current model. A similar mechanism for the combustion of metals in a high shearing regime involving melting was described by Gany and Caveny [16].

Schematic of the heat and mass transfer in the different phases of the fuel is shown in Fig. 5.

The initial development of the model including the heat transfer balance and the description of different mechanisms and fuel properties can be found in a previous work by the authors [17].

Regression rates for the mechanisms of melting, vaporization, and entrainment can be found from the heat transfer balances on the gas-liquid and liquidsolid interfaces. The radiation was neglected in the calculations.

Gas-phase flame

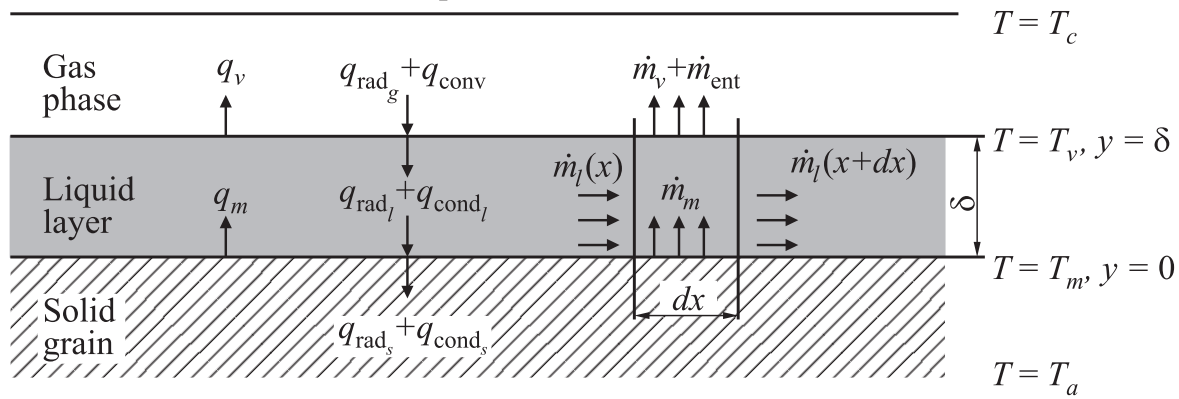

Figure 5 Schematic of heat and mass transfer of a liquefying fuel in hybrid combustion 
The overall steady state heat transfer balance can be written as

$$
q_{\mathrm{conv}}=q_{m}+q_{v} .
$$

Here, $q_{\text {conv }}$ is the heat transfer from the flame to the surface (the interface between the gas and melt layer) by convection, given by

$$
q_{\mathrm{conv}}=h\left(T_{c}-T_{v}\right)
$$

where $T_{c}$ is the combustion temperature; $T_{v}$ is the molten fuel vaporization temperature; and $h$ is the convection coefficient that can be calculated using Reynolds analogy:

$$
\mathrm{Nu}=0.023 \operatorname{Re}^{0.8} \operatorname{Pr}^{1 / 3}
$$

Here,

$$
\mathrm{Nu}=\frac{h d}{k_{g}} ; \operatorname{Re}=\frac{\rho_{g} u_{\infty} d}{\mu_{g}}=\frac{4 \dot{m}_{\mathrm{tot}}}{\mu_{g} \pi d} ; \operatorname{Pr}=\frac{\mu_{g}}{k_{g} / C_{p, g}}
$$

where $d$ is the port diameter; $\dot{m}_{\text {tot }}$ is the overall mass flow rate; $k_{g}$ is the gas conduction coefficient; $\rho_{g}$ is the gas density; $C_{p, g}$ is the gas specific heat; $\mu_{g}$ is the gas viscosity; and $u_{\infty}$ is the core gas velocity.

In Eq. (1), $q_{m}$ is the heat flux due to melting (accounting for the heating from the initial temperature $T_{a}$ to the melting temperature $T_{m}$ ):

$$
q_{m}=\rho_{s} \dot{r}_{m}\left(H_{m}+C_{p, s}\left(T_{m}-T_{a}\right)\right)
$$

where $\rho_{s}$ is the density of the solid fuel, $\dot{r}_{m}$ is the melting rate, $H_{m}$ is the enthalpy of melting, $C_{p, s}$ is the specific heat of the solid, $T_{a}$ is the temperature deep within the grain (typically, the ambient temperature); and $q_{v}$ is the heat flux required for the vaporization (accounting for the heating from the melting temperature of the solid fuel $T_{m}$ to the vaporization temperature $T_{v}$ ):

$$
q_{v}=\rho_{l} \dot{r}_{v}\left(H_{v}+C_{p, l}\left(T_{v}-T_{m}\right)\right)
$$

where $\rho_{l}$ is the density of the molten liquid; $\dot{r}_{v}$ is the rate of vaporization of liquid at the liquid-gas interface; $H_{v}$ is the enthalpy of vaporization; and $C_{p, l}$ is the specific heat of the liquid layer.

The liquid layer is thin enough to assume linear temperature profile across it, and both the liquid and thermal layers of the condensed phase are sufficiently thin compared to the port diameter to apply a flat surface approximation. Under the boundary conditions, the temperature at the liquid-gas interface is the fuel vaporization temperature, and the temperature at the liquid-solid interface is the fuel melting point. One can then state that the heat transferred by conduction through the liquid layer is

$$
q_{\operatorname{cond}_{l}}=k_{l} \frac{\Delta T}{\Delta y}=k_{l} \frac{T_{v}-T_{m}}{\delta}
$$


where $k_{l}$ is the conduction coefficient of the liquid and $\delta$ is the melt layer thickness. This heat is transferred into the solid phase causing its melting and heating; hence:

$$
k_{l} \frac{T_{v}-T_{m}}{\delta}=\rho_{s} \dot{r}_{m}\left(H_{m}+C_{p, s}\left(T_{m}-T_{a}\right)\right) .
$$

The rate of entrainment of the liquid droplets into the gas stream suggested by Karabeyoglu et al. [3] is

$$
\dot{r}_{\mathrm{ent}}=a \frac{G_{\mathrm{tot}}^{2 \alpha}}{\dot{r}^{\beta}}
$$

where $a=6.88 \cdot 10^{-14} \mathrm{~m}^{9} / \mathrm{kg}^{3}$ (for the calculations in metric units) is the entrainment parameter for paraffin; $G_{\text {tot }}$ is the overall mass flux; $\dot{r}$ is the overall regression rate (in the considered case, $\dot{r}=\dot{r}_{m}$ ); and $\alpha=1.5$ and $\beta=2$ are the parameters that are constant for the given propellant.

In the calculations, the following numerical values have been used:

$$
\begin{array}{rlrl}
k_{g} & =0.12 \mathrm{~W} /(\mathrm{m} \cdot \mathrm{K}) ; & k_{s} & =0.14 \mathrm{~W} /(\mathrm{m} \cdot \mathrm{K}) ; \\
H_{m} & =167 \cdot 10^{3} \mathrm{~J} / \mathrm{kg} ; & H_{v} & =163 \cdot 10^{3} \mathrm{~J} / \mathrm{kg} ; \\
\rho_{s} & =747 \mathrm{~kg} / \mathrm{m}^{3} ; & \rho_{l} & =450 \mathrm{~kg} / \mathrm{m}^{3} ; \\
C_{p, l} & =2.45 \cdot 10^{3} \mathrm{~J} /(\mathrm{kg} \cdot \mathrm{K}) ; C_{p, s} & =1.99 \cdot 10^{3} \mathrm{~J} /(\mathrm{kg} \cdot \mathrm{K}) ; \\
T_{m} & =343 \mathrm{~K} ; & T_{v} & =600 \mathrm{~K} ; \\
\mu_{l} & =2.24 \cdot 10^{-3} \mathrm{P} ; & \mu_{s} & =3.95 \cdot 10^{-6} \mathrm{P} .
\end{array}
$$

Applying the linear velocity profile inside the thin liquid layer and no-slip condition at the gas-liquid interface and assuming that the gas velocity is much higher than the liquid layer velocity, the shear stress can be described as

$$
\tau_{i}=\left.\mu_{g} \frac{\partial u_{g}}{\partial y}\right|_{i}=\left.\mu_{l} \frac{\partial u_{l}}{\partial y}\right|_{i}=\mu_{l} \frac{u_{i}}{\delta}
$$

where $\tau_{i}$ is the shear stress at the interface between liquid and gas; $u_{i}$ is the liquid velocity at the interface $\left(u_{i}=u_{l, \max }\right)$, and $\delta$ is the liquid layer thickness.

With an approximation of constant regression rate and port diameter along $x$, the net rate of melt generation up to a distance $x$ (subtracting the fractions removed by the vaporization and the entrainment) should compose the flow along the surface:

$$
\dot{m}_{l}=\pi d x\left(\dot{r}_{m} \rho_{s}-\left(\dot{r}_{\text {ent }}+\dot{r}_{v}\right) \rho_{l}\right)
$$

where $d$ is the grain port diameter.

The rate of melt flowing along the surface, where $u_{i} / 2$ is the average flow velocity, is

$$
\dot{m}_{l}=\pi d \frac{\delta \rho_{l} u_{i}}{2}
$$


For steady state:

$$
x\left(\dot{r}_{m} \rho_{s}-\left(\dot{r}_{\mathrm{ent}}+\dot{r}_{v}\right) \rho_{l}\right)=\frac{\delta \rho_{l} u_{i}}{2} .
$$

Solving Eqs. (2) and (4) for $u_{i}$ and $\delta$ yields:

$$
\begin{aligned}
u_{i} & =\left(\frac{2 x \tau_{i}}{\mu_{l} \rho_{l}}\left(\dot{r}_{m} \rho_{s}-\left(\dot{r}_{\mathrm{ent}}+\dot{r}_{v}\right) \rho_{l}\right)\right)^{0.5} \\
\delta & =\left(\frac{2 \mu_{l} x}{\tau_{i} \rho_{l}}\left(\dot{r}_{m} \rho_{s}-\left(\dot{r}_{\mathrm{ent}}+\dot{r}_{v}\right) \rho_{l}\right)\right)^{0.5}
\end{aligned}
$$

Calculations were made assuming average values of regression rates at the half length of the fuel grain. Shear stress at the gas-liquid interface was calculated from the correlation for a developed turbulent boundary layer in pipes:

$$
\tau_{i} \cong 0.0277 \rho_{g} u_{\infty}^{2}\left(\operatorname{Re}_{d}\right)^{-0.25}
$$

Here, $\rho_{g}$ is the gas density; $u_{\infty}$ is the core stream velocity; and $\operatorname{Re}_{d}$ is the Reynolds number calculated for the average internal diameter of the fuel grain (i. e., port diameter) $d$ :

$$
\operatorname{Re}_{d}=\frac{4 \dot{m}_{\text {tot }}}{\mu_{g} \pi d}
$$

where $\dot{m}_{\text {tot }}$ is the overall mass flow rate and $\mu_{g}$ is the gas-phase viscosity.

Figure 6 presents the dependence of the melt layer thickness on the total mass flux predicted by the model. The calculation was made for the middle

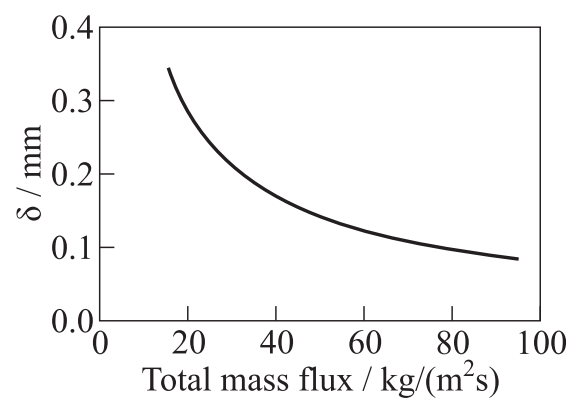

Figure 6 Model prediction of liquid layer thickness vs. total mass flux cross section along the fuel grain. One can see that the higher is the flow rate, the thinner is the liquid layer. No experimental data on the melt layer thickness have been obtained.

Figure 7 presents the different regression rate mechanisms predicted by the model and normalized by the solid fuel density to indicate the relative contribution of every individual mechanism to the overall regression rate. Calculated results are compared to the experimental data. The entrainment regression rate plays a more significant role in the overall regression rate as the mass flux increases. The mass loss contribution attributed to the melt flow along the surface is of the same order as the mass loss by the mechanism of 


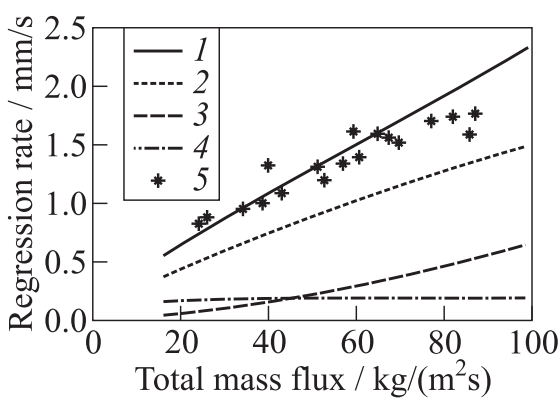

Figure 7 Model prediction of contribution of regression rate mechanisms (related to the solid fuel density) vs. the total mass flux and corresponding experimental data (overall regression rate $=$ melting rate) $: 1-$ melting rate; 2 - vaporization rate; $3-$ entrainment rate; 4 - surface melt flow; and 5- experimental data

entrainment. However, the higher is the oxidizer flow rate, the higher is the mass loss due to the mechanisms of vaporization and entrainment, which make liquid layer thinner. This observation is compatible with the trend shown in Fig. 6 .

The model predicts that in the range tested, the contribution of the vaporization to the overall regression rate (equal to the melting regression rate) is more significant than the contribution of the entrainment. Within the uncertainty of the different physical properties yielding an uncertainty of $\pm 15 \%$ in the regression rate prediction, a good agreement is demonstrated between the model prediction and test results.

The behavior of the different mechanisms of the regression rate and the thickness of the liquid layer along the combustion chamber at a given cross section was also examined. The calculations were made using the mass conservation equation in the control volume described in Fig. 5 over a length $d x$ :

$$
\dot{m}_{l_{x+d x}}-\dot{m}_{l_{x}}=\dot{m}_{m}-\dot{m}_{v}-\dot{m}_{\mathrm{ent}}=\pi d d x\left(\rho_{s} \dot{r}_{m}-\rho_{l}\left(\dot{r}_{v}+\dot{r}_{\mathrm{ent}}\right)\right)
$$

where the melt flow rate at a distance $x$ from the leading edge of the grain is

$$
\dot{m}_{l_{x}}=\left(\pi d \frac{\delta \rho_{l} u_{i}}{2}\right)_{x} .
$$

The thickness of the melt layer changes along the grain, and liquid flow average velocity was calculated from Eq. (3). The regression rate mechanisms were calculated from heat transfer balances as described above.

Figure 8 presents the contribution of each mechanism to the overall regression rate (equal to the melting rate) along the fuel grain for a representative overall port mass flux of $45 \mathrm{~kg} /\left(\mathrm{m}^{2} \mathrm{~s}\right)$. Figure 9 presents the variation of the melt layer thickness along the grain for the same total mass flux. 


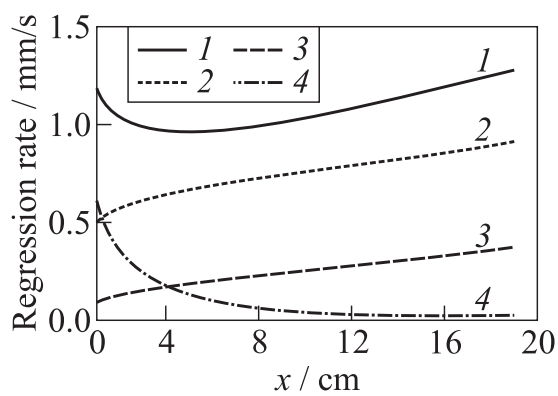

Figure 8 Model prediction of regression rate contributions of the different mechanisms along the fuel grain for a total port mass flux of $45 \mathrm{~kg} /\left(\mathrm{m}^{2} \mathrm{~s}\right.$ ) (melting rate represents the overall fuel regression rate): 1 - melting rate; 2 - vaporization rate; 3 - entrainment rate; and 4 - surface melt flow

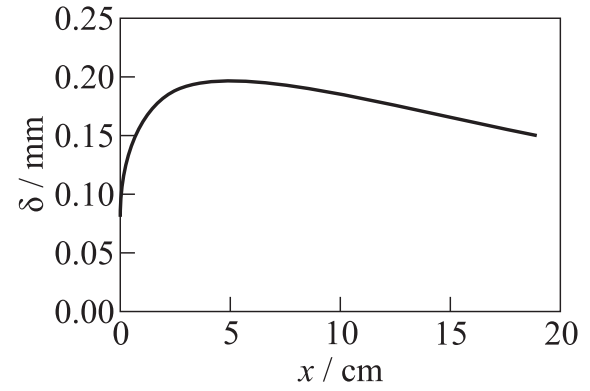

Figure 9 Prediction of liquid layer thickness along the fuel grain for a total mass flux of $45 \mathrm{~kg} /\left(\mathrm{m}^{2} \mathrm{~s}\right)$
It can be observed that the melting regression rate reaches a minimum value relatively close to the leading edge and later increases along the grain. The same trend of the overall regression rate was observed by Gariani et al. [18] and Chiaverini et al. [19] for the nonliquefying fuels.

The overall mass consumption by every individual mechanism during combustion was calculated. It was found that $67 \%$ of the molten liquid is vaporized, $21 \%$ enters the flow by the entrainment mechanism, and

$12 \%$ reaches the end of the combustion chamber as a flowing liquid layer. The model predicts that for a total port mass flux of $45 \mathrm{~kg} /\left(\mathrm{m}^{2} \mathrm{~s}\right)$, an overall molten mass of about $5 \mathrm{~g}$ should leave the combustion chamber by flowing along the surface (within the melt layer) during a 5 -second firing test of the experimental motor of this investigation. It is of the same order as the amount of molten material accumulated in the aft mixing chamber in actual tests, indicating the significance of this mass transfer mechanism in liquefying fuels.

\section{CONCLUDING REMARKS}

According to the results presented in this work, paraffin can be a good solution for regression rate enhancement in hybrid engines. 
Model predictions of regression rate of a liquefying fuel yield fair agreement with the test data. The very low heat of vaporization of paraffin as well as its low vaporization temperature results in a significant contribution of the vaporization rate to the overall regression rate, more than the entrainment mechanism in the range tested.

A mechanism of liquid layer flow along the fuel surface has been added in the present model. It is shown that the mass transfer by this mechanism is of the same order as the mass loss by the vaporization and the entrainment and, hence, should not be neglected.

The prediction of the overall mass loss due to the different mechanisms during a firing test indicated that about $12 \%$ of the fuel melted during combustion should leave the combustion chamber by flowing along the surface of the fuel grain. Actual tests revealed that this amount is of the order of the mass of molten fuel accumulated in the aft mixing chamber, pointing out the significance of this mass transfer mechanism in liquefying fuels. Furthermore, accumulation of a molten material in the aft mixing chamber, which may only partially burn, may be considered a loss in practical systems, adds parasite mass in the motor, and potentially reduces the overall system performance.

This article has concentrated on the combustion phenomena and has not dealt with paraffin mechanical properties which are inferior to those of polymeric fuels.

\section{REFERENCES}

1. Altman, A., and A. Holzman. 2007. Overview and history of hybrid rocket propulsion. In: Fundamentals of hybrid rocket combustion and propulsion. Eds. M. J. Chiaverini and K. K. Kuo. Progress in astronautics and aeronautics ser. Reston, VA: AIAA. 218:1-36.

2. Karabeyoglu, M. A., B. J. Cantwell, and D. Altman. 2001. Development and testing of paraffin-based hybrid rocket fuels. AIAA Paper No. 2001-4503.

3. Karabeyoglu, M. A., D. Altman, and B. J. Cantwell. 2002. Combustion of liquefying hybrid propellants: Part 1. General theory. J. Propul. Power 18(3):610-20.

4. Karabeyoglu, M. A., and B. J. Cantwell. 2002. Combustion of liquefying hybrid propellants: Part 2. Stability of liquid films. J. Propul. Power 18(3):621-30.

5. Karabeyoglu, A., G. Zilliac, B. J. Cantwell, S. DeZilwa, and P. Castellucci. 2004. Scale-up tests of high regression rate paraffin-based hybrid rocket fuels. J. Propul. Power 20(6):1037-45.

6. Karabeyoglu, A., B. J. Cantwell, and J. Stevens. 2005. Evaluation of homologus series of normal-alkanes as hybrid rocket fuel. AIAA Paper No. 2005-3908.

7. Luchini, C. B., P. Wynne, M. K. Hudson, and S. Rooke. 1996. Hydrocarbon hybrid rocket fuel regression rate studies. AIAA Paper No. 96-2595.

8. Evans, B., N. A. Favorito, E. Boyer, G. A. Risha, R. B. Wehrman, and K. K. Kuo. 2004. Characterization of nano-sized energetic particle enhancement of solid-fuel 
burning rates in an X-ray transparent hybrid rocket engine. AIAA Paper No. 20043821.

9. Gany, A., and A. Lazarev. 2007. Fundamentals and new trends in hybrid propulsion. 6th High Energy Materials Conference and Exhibit (HEMCE-07). Chennai, India.

10. Lee, T. S., and H. L. Tsai. 2006. Fuel regression rate in a paraffin-HTPB / gaseousoxygen hybrid rocket. 5th Taiwan-Indonesia Workshop on Aeronautical Science, Technology and Industry. Tainan, Taiwan.

11. Pelletier, N., and Y. Maisonneuve. 2007. New ways of research for hybrid propulsion. 7th Symposium (International) on Launcher Technologies. Barcelona, Spain.

12. Pelletier, N., and Y. Maisonneuve. 2008. Paraffin-based hybrid fuel: Model of regression and experiments. 2nd Symposium (International) on Propulsion for Space Transportation. Heraklion, Crete.

13. Marxman, G., and M. Gilbert. 1963. Turbulent boundary layer combustion in the hybrid rocket. 9th Symposium (International) on Combustion. The Combustion Institute. 1337-49.

14. Marxman, G. A., C. E. Wooldridge, and R. J. Muzzy. 1964. Fundamentals of hybrid boundary combustion, heterogeneous combustion. Progress in astronautics and aeronautics ser. New-York: Academic Press. 15:485-522.

15. Marxman, G. 1965. Combustion in the turbulent boundary layer on a vaporizing surface. 10th Symposium (International) on Combustion. The Combustion Institute. $1337-49$.

16. Gany, A., and L.H. Caveny. 1982. Mechanism of chemical and physical gas-metal interactions in very high shearing regimes. 19th Symposium (International) on Combustion. The Combustion Institute. 731-40.

17. Weinstein, A., and A. Gany. 2009. Investigation of paraffin-based fuels in hybrid combustors. 8th Symposium (International) on Special Topics in Chemical Propulsion (8-ISICP). Cape Town, South Africa.

18. Gariani, G., F. Maggi, and L. Galfetti. 2011. Numerical simulation of HTPB combustion in a 2D hybrid slab combustor. Acta Astronautica 69(5-6):289-96.

19. Chiaverini, M. J., N. Serin, D. K. Jhonson, Y. Lu, K. K. Kuo, and G. A. Risha. 2000. Regression rate behavior of hybrid rocket solid fuels. J. Propul. Power 16(1):12532. 